\title{
DiAGNOSES DE BORDO: POSSÍVEIS RUMOS DA EVOLUÇÃo DO OBDBR-2
}

Oscar Javier Duque ${ }^{1}$, Guido Roewer Jr. ${ }^{2.1}$ e Paolo Furlan ${ }^{2.2}$

${ }^{1}$ FEV Brasil Tecnologia de Motores

${ }^{2}$ Magneti Marelli Sistemas Automotivos

duque@,fev.com, guido.roewer@magnetimarelli.com, paolo.furlan@magnetimarelli.com,

\begin{abstract}
RESUMO
O presente trabalho visa mostrar a possibilidade de evolução da normativa OBDBr-2, demonstrando que é oportuno caminhar na mesma direção dos mais exigentes padrões internacionais visando um futuro alinhamento das normativas, mesmo levando-se em consideração os fatores complicadores da tecnologia Flex Fuel.
\end{abstract}

A redução dos limites de emissões OBDBr-2 seguindo a tendência de redução daqueles das emissões de escapamento e levando-se em consideração possíveis alterações nos fatores de deterioração (Durabilidade de $80000 \mathrm{~km}$ para $120000 \mathrm{~km}$ ou $160000 \mathrm{~km}$ ), a criação de um limite para os óxidos de nitrogênio (NOx) para a diagnose do catalisador que conta apenas com o limite para hidrocarbonetos (NMHC), e a obrigatoriedade de se manter as diagnoses ativas em qualquer relação Ar/Combustível e não apenas nas relações correspondentes a Etanol (E100) e Gasolina (E22), são medidas possíveis de serem implantadas.

Os sistemas mais modernos já estão preparados para estas mudanças, como será apresentado neste trabalho, restando apenas a calibração dos parâmetros de funcionamento das diagnoses.

\section{INTRODUÇÃO}

Para reduzir os efeitos da poluição do ar devido ao aumento do tráfego veicular, foi implementado em 1988 pelas autoridades do estado da Califórnia a primeira fase de legislação CARB (California Air Resources Board) para veículos a gasolina, com a exigência adicional da implementação de sistemas de automonitoramento em veículos novos comercializados (OBDI). Estes sistemas deviam comprovar o correto funcionamento dos componentes elétricos cujas falhas poderiam causar um aumento das emissões até um limite conhecido como limite OBD. Em 1996, foi adotado o sistema OBDII, que além de conter as diagnoses elétricas, tem como objetivo monitorar o correto funcionamento de outros sistemas, como os sensores de oxigênio, o catalisador, assim com a deteç̧ão de falhas na combustão (Misfire), além de uma redução no limite de emissões OBD. No mercado europeu foi desenvolvido o sistema EOBD, com algumas modificações do sistema OBD original, entrando em vigor em 2001. 
Já no Brasil decidiu-se a partir da metade da década de 80, tomar ações e implementar programas para controlar as emissões de veículos e, devido ao número crescente da frota circulante no país, que quase quadruplicou nos últimos 20 anos (Fig.1), as autoridades, juntamente com os órgãos fiscalizadores e entidades técnicas, decidiram a partir de 2007 introduzir os sistemas de monitoramento OBD, denominado OBDBr-1 e baseado no OBDI (diagnose elétrico dos componentes).

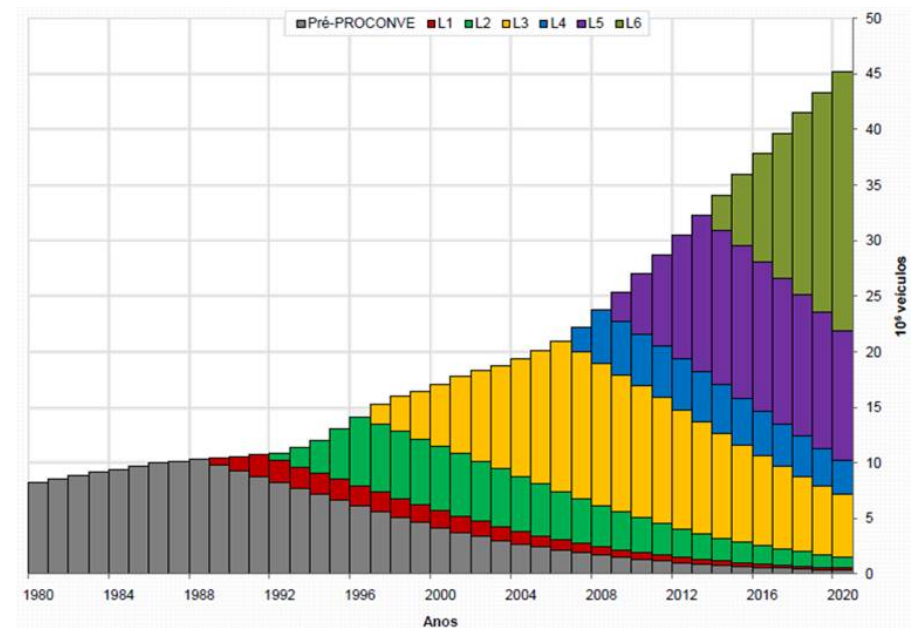

Figura 1. Frota de automóveis e comerciais leves Otto no Brasil [1]

Em 2010, foi adotada a primeira evolução do sistema OBD, denominada OBDBr-2, que além do monitoramento previsto pelo sistema OBDBr-1, analisa o comportamento do sensor de oxigênio pré-catalisador ou "upstream", a eficiência de conversão do catalisador em função do NMHC e as falhas de combustão.

Para 2014, estão previstas diversas atualizações nas legislações de emissões dos principais mercados do mundo (Figura 2), tendo a introdução da normativa EU6 juntamente com sua atualização OBD na Europa, a primeira fase do LEVIII e OBDIII nos Estados Unidos, e o início da legislação baseada nos limites de emissões definidos pelo Proconve L6 no Brasil. As relevantes diferenças dos atuais sistemas OBD são apresentados na Figura 3.

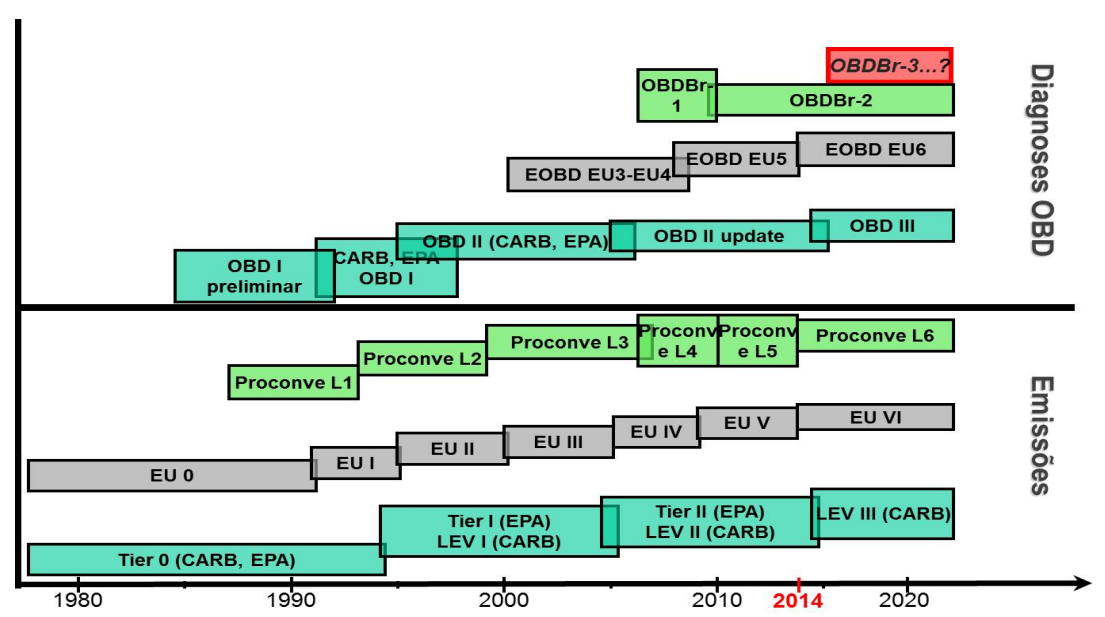

Figura 2. Evolução dos programas de emissões veiculares e diagnoses OBD [2] 


\begin{tabular}{|c|c|c|c|}
\hline & OBD-II (USA) & EOBD EU6 & $\mathrm{OBDBr}-2$ \\
\hline Diagnose Catalisador (NMHC) & $\sqrt{ }$ & $\sqrt{ }$ & $\sqrt{ }$ \\
\hline Diagnose Catalisador (NOx) & $\sqrt{ }$ & $\sqrt{ }$ & $\mathrm{X}$ \\
\hline Diagnose resposta sonda Upstream & $\sqrt{ }$ & $\sqrt{ }$ & $\sqrt{ }$ \\
\hline Diagnose resposta sonda Downstream & $\sqrt{ }$ & $\sqrt{ }$ & $\mathrm{X}$ \\
\hline Diagnose Misfire & $\sqrt{ }$ & $\sqrt{ }$ & $\sqrt{ }$ \\
\hline Diagnose Fuel System & $\sqrt{ }$ & $\sqrt{ }$ & $\mathrm{x}$ \\
\hline Diagnoses elétricas & $\sqrt{ }$ & $\sqrt{ }$ & $\sqrt{ }$ \\
\hline Diagnose Ar secundário & $\sqrt{ }$ & $\sqrt{ }$ & $\mathrm{X}$ \\
\hline Diagnose Cylinder Imbalance & $\sqrt{ }$ & $\mathrm{x}$ & $\mathrm{X}$ \\
\hline In Use Monitor Performance Ratios (IUMPR) & $\sqrt{ }$ & $\sqrt{ }$ & $\mathrm{X}$ \\
\hline Sistemas Flex (Álcool e Gasolina) & $\mathrm{X}$ & $\mathrm{X}$ & $\sqrt{ }$ \\
\hline
\end{tabular}

Figura 3. Comparação dos programas OBD atuais nos EUA, Europa e Brasil

Um dos principais desafios para o setor automotivo brasileiro foi a implementação dos sistemas OBD em um mercado no qual cerca de $90 \%$ dos veículos leves vendidos no último ano são Flex. Isto implica em assegurar o correto funcionamento do sistema OBDBr-2 tanto pra gasolina como para etanol, mesmo que estes sejam combustíveis com características bem diferentes [2]. Ao comparar as exigências do sistema OBD, é preciso levar em consideração as particularidades do etanol como combustível. Entre estas particularidades está o aumento na evaporação proveniente do cárter do motor ("blow by"), diferença de ponto de ignição e de frequência de comutação da sonda lambda em relação ao aplicado para o funcionamento do motor à gasolina. Entretanto, tecnologias já desenvolvidas no país permitem contornar possíveis problemas advindos de tais diferenças e tornar possível caminhar em direção a uma futura aproximação das normas relativas às diagnoses de bordo presentes nos mercados mais exigentes do mundo.

As Figuras 4 e 5 apresentam um comparativo dos limites de emissões de escapamento e limites OBD para NMHC, NOx e CO na Europa e no Brasil. A evolução da legislação Proconve, reduzindo as emissões de escapamento em 2014 sem redução dos limites OBD, podería ser comparada à evolução da normativa europeia de EU3 para EU4.

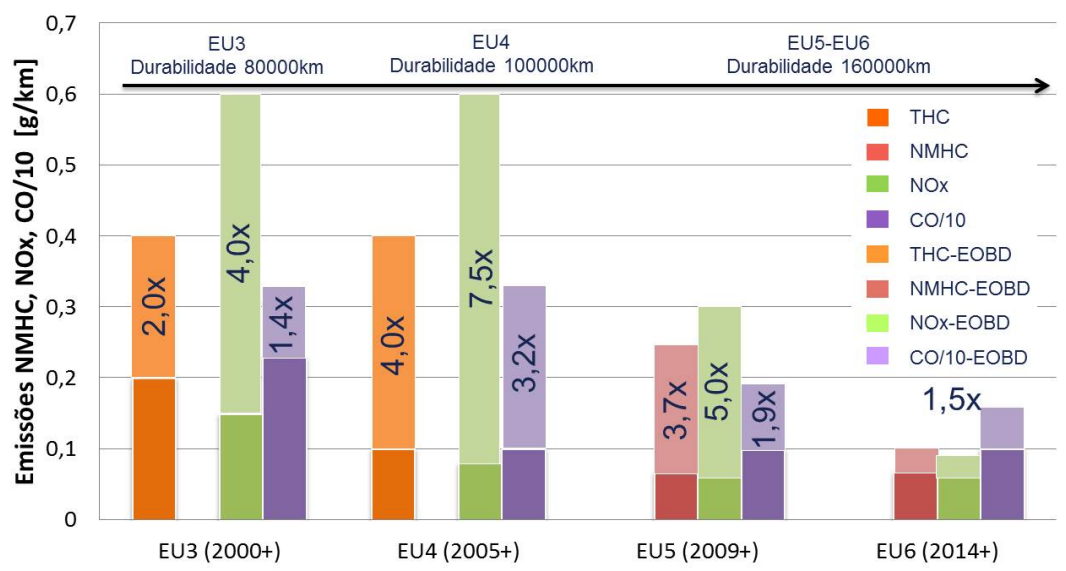

Figura 4. Evolução dos limites de escapamento e OBD na Europa [3] 


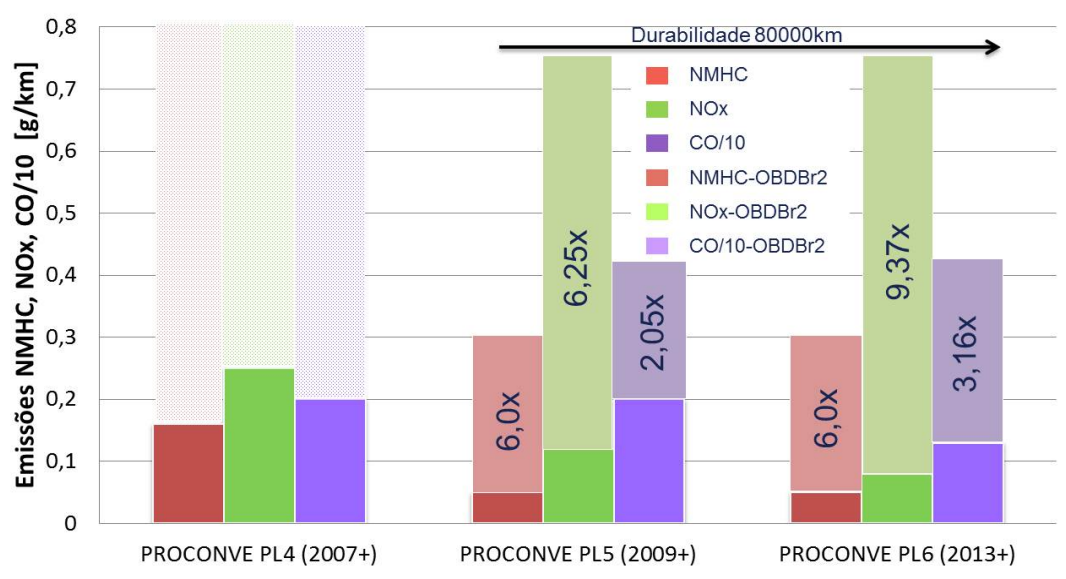

Figura 5. Evolução dos limites de escapamento e OBD no Brasil

\section{LIMITES OBD NO BRASIL: POSSÍVEIS CENARIOS}

A introdução em 2010 da normativa OBDBr-2 implantou limites de emissões elevados, pois se tratava de um primeiro passo na criação deste tipo de legislação. Esta implantação transcorreu sem maiores problemas e é perfeitamente possível reduzir os limites OBD como será demonstrado a seguir.

No padrão atual (Figura 6) tem-se uma ampla faixa dentro da qual pode-se detectar a falha, o que requer uma menor precisão das diagnoses. Porém, a maior dificuldade encontrada durante a fase de calibração é conseguir atingir os limites $\mathrm{OBDBr}-2$, pois mesmo simulando condições extremas de falha, há casos em que não é possível atingir-os

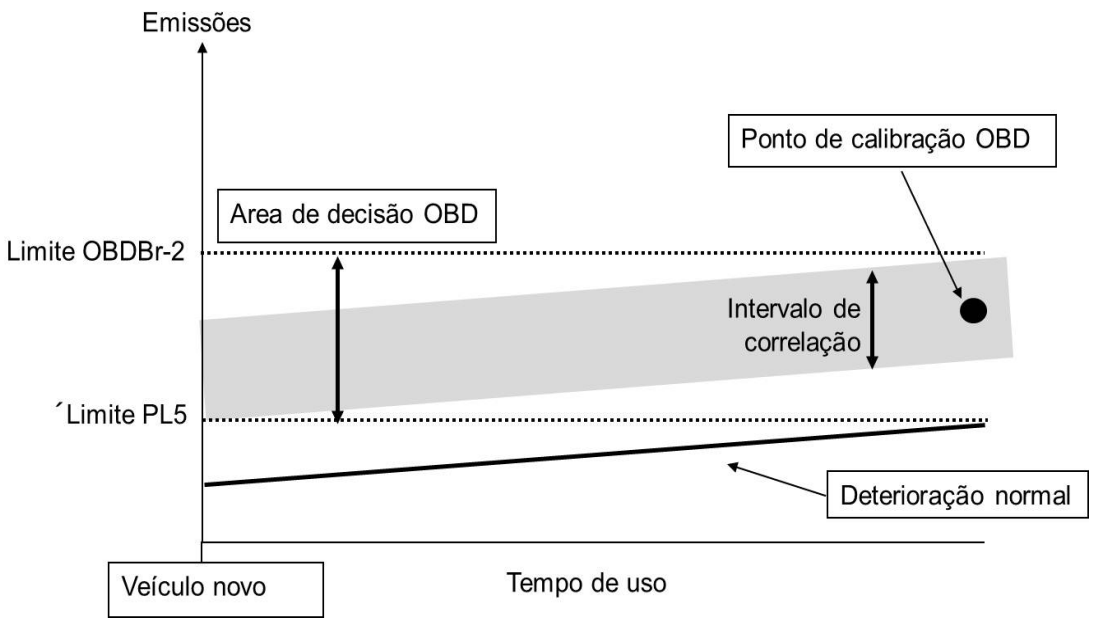

Figura 6. Área de calibração OBD atual

Como um primeiro cenário de novos limites $\mathrm{OBD}$, tomou-se como base a diminuição experimentada pelos limites de escapamento. Tomando-se a redução em gramas que sofreram os limites Proconve de PL5 para PL6, e transportando esta mesma redução para os limites 
OBD (diferença absoluta em gramas), tem-se o primeiro cenário de redução, apresentado como "OBDBr-3_1".

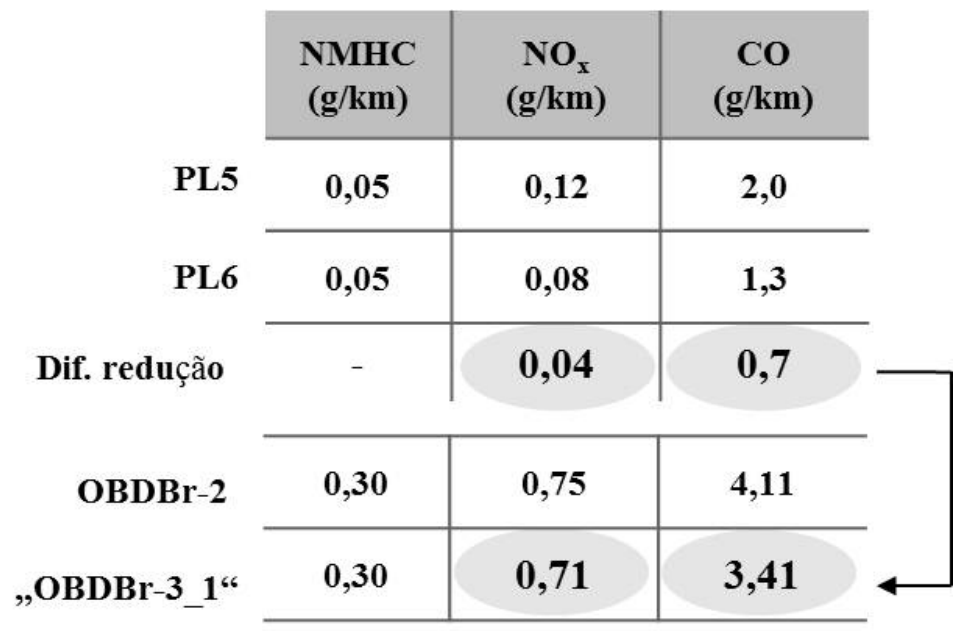

Tabela 1. Cenário 1: diferença absoluta em gramas

Embora importante nos limites de escapamento, esta primeira aproximação não teria impacto apreciável nos limites OBD, uma vez que as emissões de veículos, quando simulada uma falha, podem apresentar dispersões de até $20 \%$. Entretanto, quando aplicada uma redução percentual equivalente àquela sofrida pelos limites de emissões de escapamento, nota-se uma redução considerável nos limites $\mathrm{OBD}$, como pode ser visto na Tabela 2.

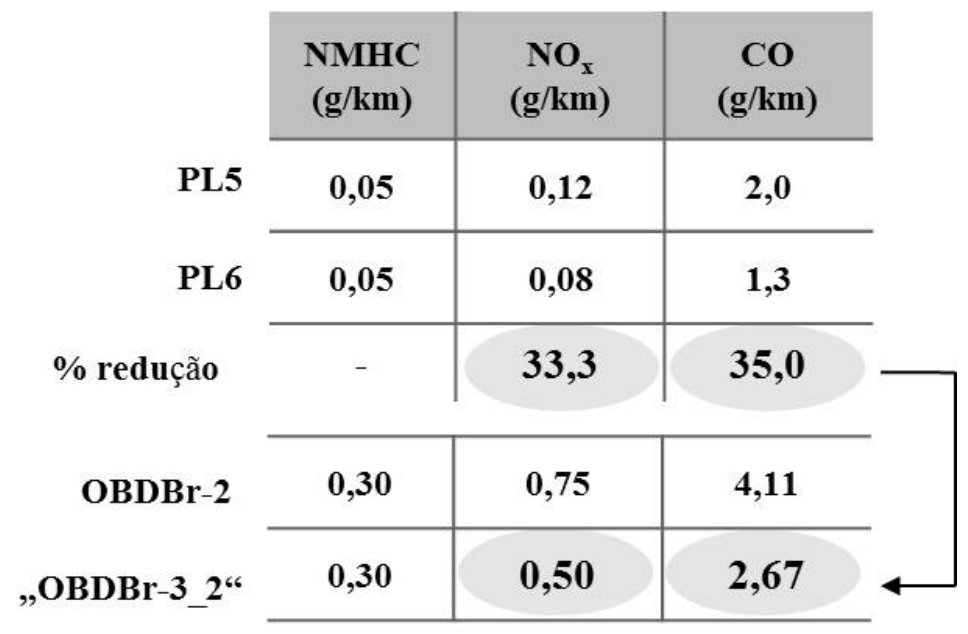

Tabela 2. Cenário 2: diferença percentual Proconve

O impacto imediato pode ser visto na figura 7 , no qual vê-se a diminuição da faixa de detecção da falha. 


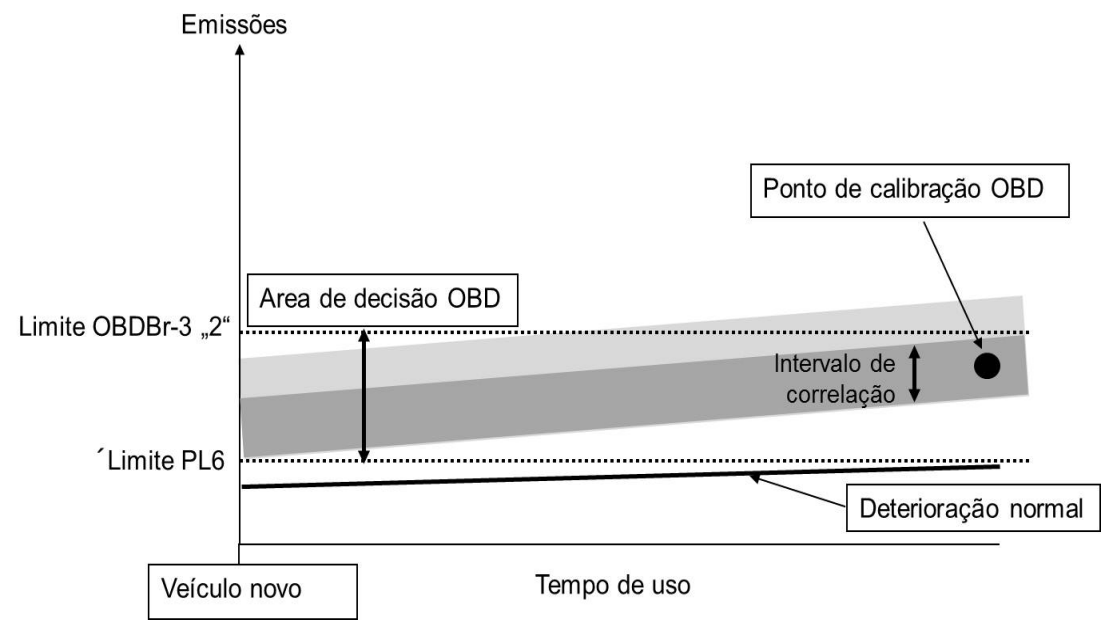

Figura 7. Area de calibração OBD usando o cenário 2

Outro cenário de redução dos limites OBD pode ser obtido levando-se em consideração a redução percentual que tais limites sofreram na evolução da normativa europeia (Tabela 3). Nota-se que tal redução, na passagem de Euro4 para Euro5+, quando aplicada aos limites OBD brasileiros, faz com que estes sejam consideravelmente próximos dos limites PL5.

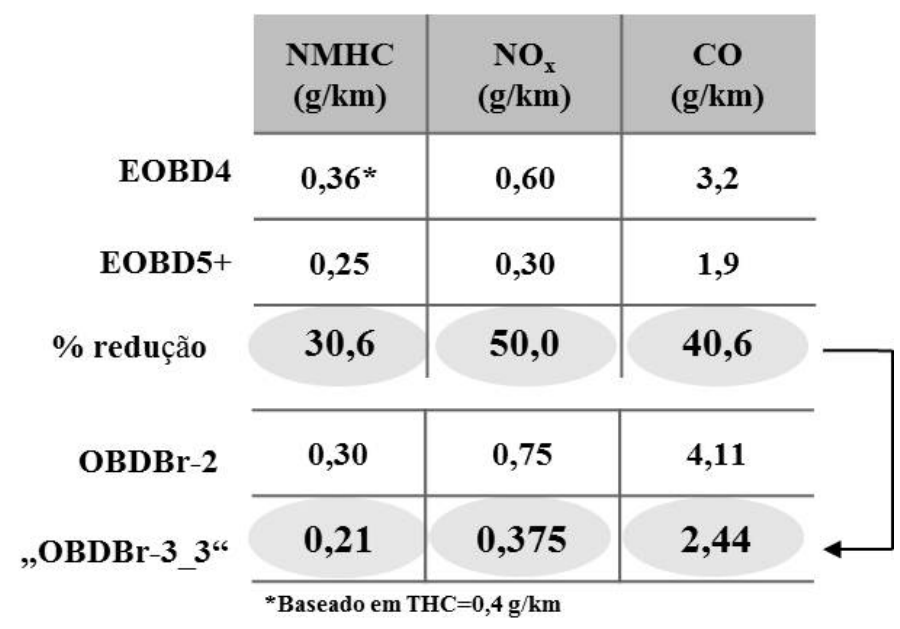

Tabela 3. Cenário 3: diferença percentual EOBD

Este cenário, o mais severo entre os apresentados neste trabalho, acarretaria um intenso trabalho de calibração das diagnoses visando aumentar a precisão em seus resultados e o nível de certeza quando uma falha é detectada. Isto pode ser notado observando-se a Figura 8. 


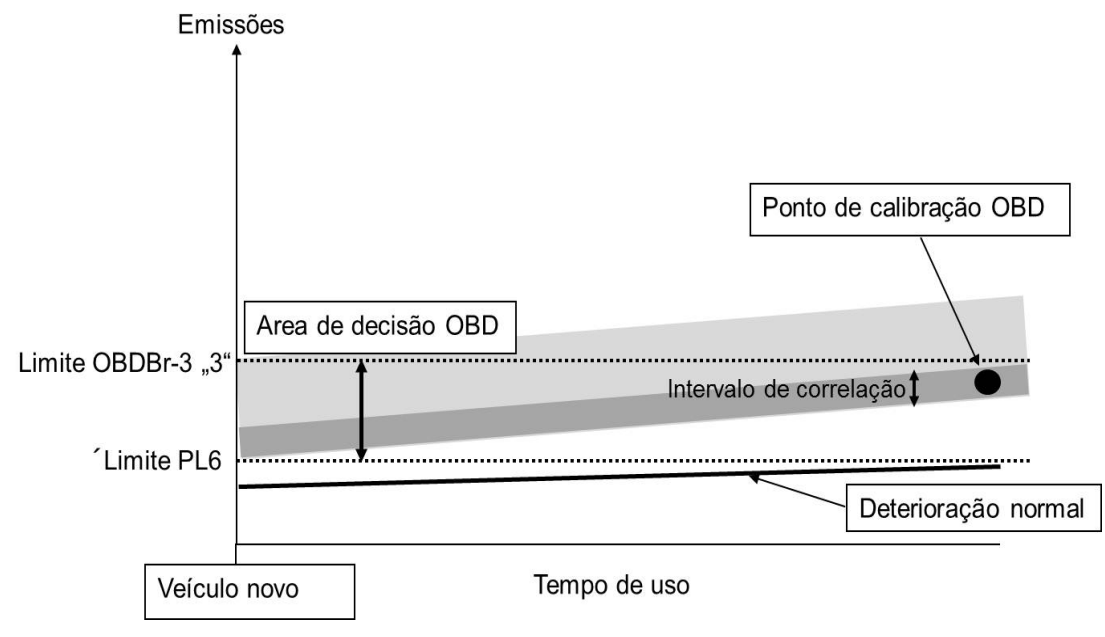

Figura 8. Area de calibração OBD usando o cenário 3

Acompanhando a exigência de se reduzir os limites OBD é imediato pensar no aumento da durabilidade dos sistemas de controle de emissões nos veículos. Na Europa, a evolução da normativa EU4 para EU5 adicionou também um aumento na durabilidade exigida para atender os limites de emissões, passando de $100000 \mathrm{~km}$ para $160000 \mathrm{~km}$, ou seja, incremento de $60 \%$. A durabilidade atual exigida na normativa Proconve é de $80000 \mathrm{~km}$. Considerando-se que no Brasil a idade média da frota de veículos leves circulante é de 8,75 anos [4], e que a rodagem média anual em áreas como São Paulo é de $14000 \mathrm{~km} /$ ano para veículos com idades entre 4 e 20 anos [5], tem-se uma quilometragem estimada de:

$14000 \mathrm{~km} /$ ano $\times 8,75$ anos $=122500 \mathrm{~km}$

Para procedimentos de homologação de emissões e OBD, a normativa exige o uso de dispositivos representativos da vida útil do veículo conforme NBR-14008 ou em sua ausência, os fabricantes de veículos devem levantar fatores de deterioração de emissões (DF) para cada poluente [6]. A seguinte tabela sumariza os fatores de deterioração exigidos no Brasil em relação àqueles europeus.

\begin{tabular}{|l|c|c|}
\cline { 2 - 3 } \multicolumn{1}{c|}{} & OBDBr-2 & EU5+ ; EU6 \\
\hline Durabilidade & $80000 \mathrm{~km}$ & $160000 \mathrm{~km}$ \\
\hline DF NMHC & 1,2 & 1,3 \\
\hline DF CO & 1,2 & 1,5 \\
\hline DF NOx & 1,1 & 1,6 \\
\hline
\end{tabular}

Tabela 4. Durabilidade e fatores de deterioração

Outra possivel evolução da norma OBD seria então, utilizar uma nova durabilidade mínima de $120000 \mathrm{~km}$, mais ajustada ao cálculo apresentado acima. Esta nova durabilidade seria uma média entre a atual $(80 \mathrm{~K})$ e a exigida na Europa (160K). Da mesma forma, poderiam ser acrescentados os fatores de deterioração como média dos valores da Tabela 4, tendo assim para $\mathrm{NMHC}, \mathrm{NOx}$ e $\mathrm{CO}$ os fatores $1.25,1.35$ e 1.35 respectivamente. $\mathrm{O}$ aumento na durabilidade asseguraria que as emissões de escape seriam mantidas dentro dos limites por um período $50 \%$ maior do que atualmente, ou seja, por aproximadamente $100 \%$ da vida útil média atual do veículo, com evidente ganho ambiental. 
Frente a estes cenários de redução dos limites OBD, foram analisados os impactos sobre cada poluente, tomando como base resultados médios de emissões em etapa de homologação OBD em quatro programas atualmente comercializados no mercado brasileiro. A Figura 9 apresenta a variação nas emissões de $\mathrm{CO}$ em relação aos limites $\mathrm{OBD}$ atuais e os cenários de redução sugeridos neste trabalho. Além da influência dos limites, estudou-se o impacto da implementação de $120000 \mathrm{~km}$ como durabilidade mínima.

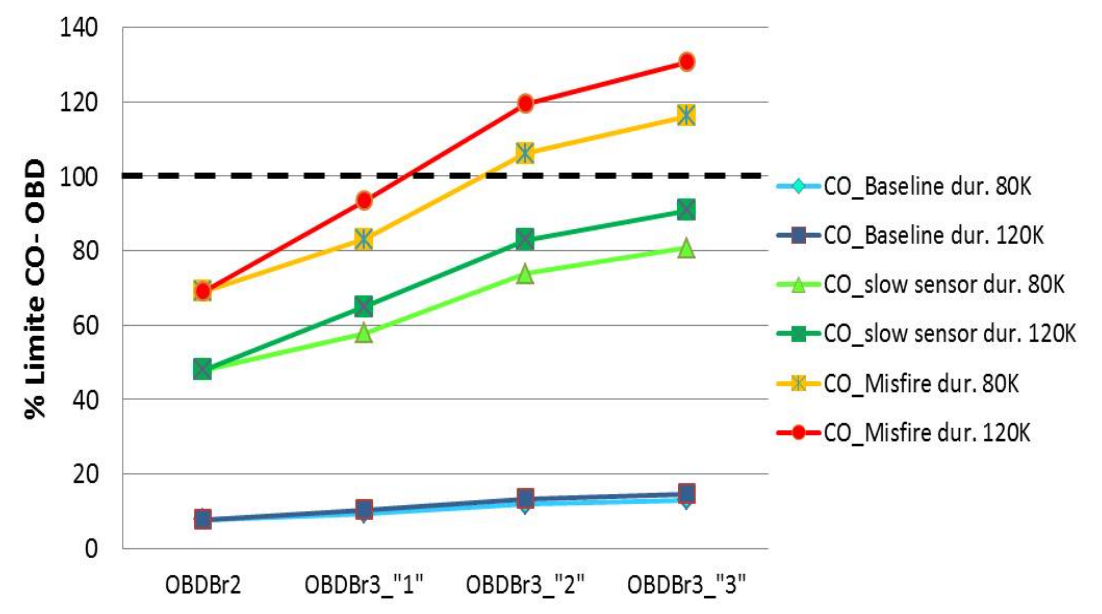

Figura 9. Impacto nas emissões de CO usando os três cenários OBD

Os valores médios das emissões de $\mathrm{CO}$ dos veículos utilizados neste trabalho com relação aos limites OBD atuais atingiram $48 \%$ para falha de resposta lenta da sonda "upstream" e $70 \%$ para falhas de combustão (Misfire), limitado pelo impacto na dirigibilidade do veículo. Correlacionando estes valores ao limite OBDBr3_"1" para CO, nota-se que mesmo com fatores de deterioração maiores, as emissões ainda atenderiam este cenário. Com respeito aos cenários OBDBr3_"2" e "3", é ultrapassado o limite de emissões quando aplicado o mesmo nível de falhas de combustão (Misfire), porém nos ensaios de resposta da sonda os resultados ficaram entre $80 \%$ e $90 \%$ dos limites. Os resultados da diagnose de catalisador não foram considerados devido ao fato da normativa exigir somente o monitoramento do NMHC para esta diagnose.

Com relação ao NOx, foi obtido um valor inicial de 53\% do limite OBDBr-2 para a diagnose da sonda e de $94 \%$ para um catalisador deteriorado. É importante lembrar que a legislação brasileira atual não contempla o monitoramento do NOx para a diagnose de catalisador. Este assunto também será abordado neste trabalho.

As emissões de NOx, quando aplicada a falha do sensor de oxigênio, ultrapassaram levemente os limites OBDBr3_"3" no caso da deterioração de $80 \mathrm{~K}$, e em $20 \%$ para $120 \mathrm{~K}$. 


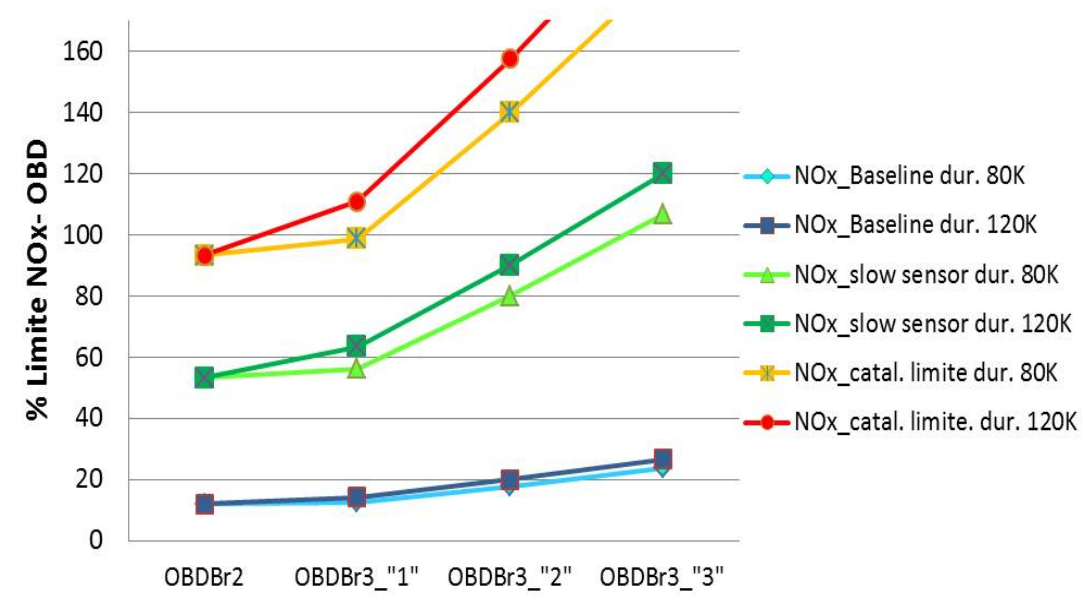

Figura 10. Impacto nas Emissões de NOx usando os três cenários OBD

Do último poluente, NMHC, alterou-se o limite somente no cenário OBDBr3 "3", pois as duas propostas anteriores são baseadas na mudança dos limites PL5 a PL6, a qual não modifica os valores máximos de NMHC.

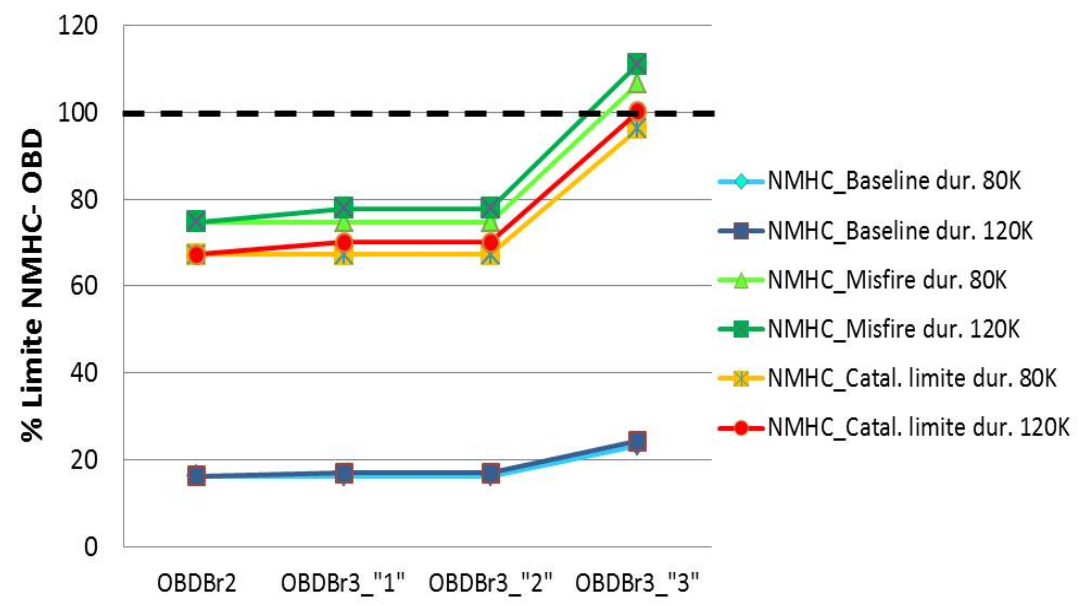

Figura 11. Impacto nas Emissões de NMHC usando os três cenários OBD

Os resultados médios para o catalisador deteriorado mostram um atendimento aos novos limites, apresentando valores próximos a $100 \%$ destes. Para a diagnose de Misfire, os limites OBDBr3_"3" significariam aumento nas emissões de até 10\% acima do limite de NMHC.

Pode ser concluido com esta pesquisa, que no caso mais "brando" da evolução dos limites, não seria necessário uma atualização na calibração para atendê-los. As propostas 2 e 3, mais rigorosas, exigiriam uma revisão da calibração OBD, pois as intensidades nas simulações de falha precisariam ser alteradas. Entretanto, estes dados representam uma média entre os diversos veículos estudados, dentre os quais, alguns já estariam preparados para todos os cenários de redução apresentados, mesmo com o novo fator de deterioração. 


\section{SISTEMAS OBD ATIVOS EM QUALQUER FAIXA DE COMBUSTÍVEL}

Segundo o ponto 2.3.6 do anexo II da instrução normativa $\mathrm{n}^{\circ} 24$ do IBAMA [6], " $O$ fabricante pode ainda desabilitar os monitores de eficiência do(s) catalisador(es) e de deterioração do(s) sensor(es) de oxigênio quando o veículo multicombustivel estiver utilizando combustível fora das seguintes faixas de concentração de álcool, uma vez estabilizada a fase de reconhecimento e aprendizado do tipo de combustivel":

- E19 a E30

- E90 a E100

Os critérios de escolha de combustivel dos propietarios de veículos Flex no Brasil, são bastante subjetivos. De um modo geral, o preço predomina como o principal critério de decisão. Contudo, há consumidores que criaram o hábito de utilizar somente um combustível, independentemente do preço. Ou seja, a percepção de opção de escolha não significa efetivamente que haverá uso dos dois combustíveis. Há também um grupo de consumidores que utiliza somente gasolina, por associar problemas na partida e no funcionamento do veículo a frio, como os que haviam antes da introdução da injeção eletrônica, ao abastecimento com etanol [7].

Além do preço, pesquisas do Ministério de Minas e Energia apontan secundariamente, como influenciadores da escolha do combustível a ser utilizado, os seguintes critérios de decisão:

- Preço da gasolina aditivada

- Trajeto que será feito

- Último abastecimento

- Clima

- Meio ambiente

Contudo, segundo pesquisa realizada pelo EPE [7], existe uma parcela de proprietários de veículos flex que costumam alternar os abastecimentos com E22 e E100, ou mesmo misturar os dois combustiveis durante o abastecimento, dando origem a faixas de teor de etanol nas quais não é exigida a habilitação das diagnoses de catalisador e de sensor de oxigênio; $\mathrm{Ou}$ seja, provavelmente há veículos que na maior parte do tempo estão dispensados de detectar falhas dos sistemas de controle de emissões de poluentes.

Nos sistemas modernos de controle do motor, as funções encarregadas do diagnóstico de sonda e de catalisador, são capazes de trabalhar com qualquer das misturas de combustivel possiveis no Brasil, desde E19 até E100. Em pesquisa realizada no laboratório de emissões veiculares da Magneti Marelli, foram realizados ensaios de emissões baseline usando um catalisador com $80000 \mathrm{~km}$ rodados, para avaliar o comportamento dos poluentes em todas as faixas de concentração de etanol, usando um veículo flex disponivel no mercado (Tabela 5), equipado com sistema SFS® (Software Flexfuel Sensor) da Magneti Marelli. 


\begin{tabular}{|l|l|}
\hline Cilindrada total & $1,6 \mathrm{~L}$ \\
\hline Aspiração & Natural \\
\hline Injeção Eletrônica & Magneti Marelli IAW \\
\hline Combustível & Flex \\
\hline Número de válvulas & 16 \\
\hline Sistema de emissões & Proconve L5 \\
\hline Sistema de control OBD & OBDBr-2 \\
\hline
\end{tabular}

Tabela 5. Características do veículo utilizado na pesquisa

A Figura 12 mostra os resultados das emissões em relação aos limites PL5. Observa-se que os limites sao atendidos com qualquer mistura de combustivel.

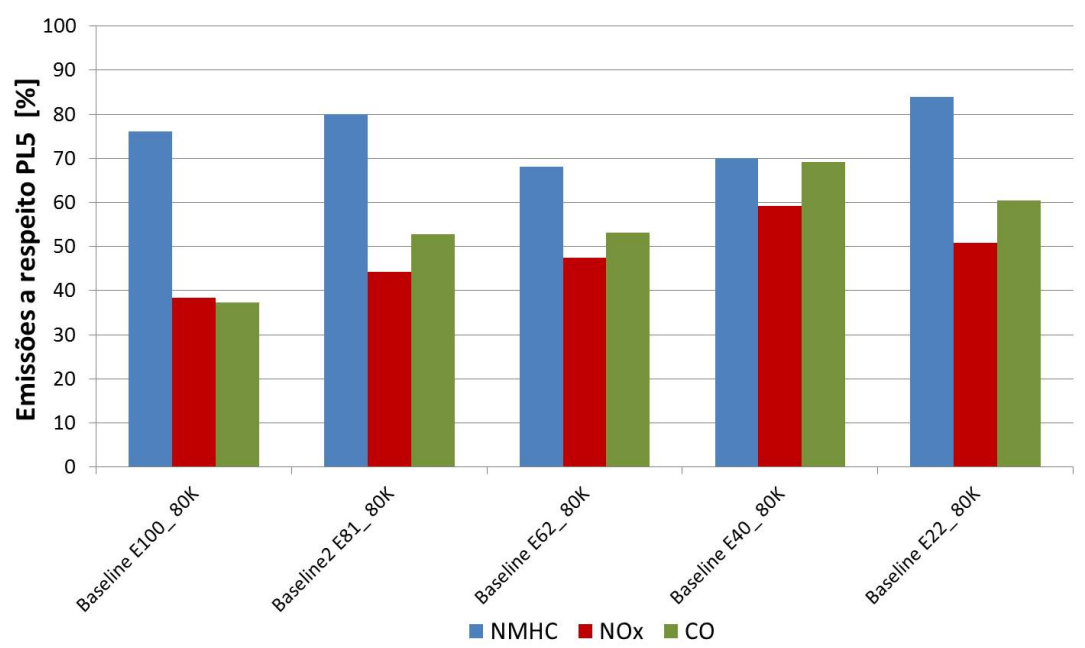

Figura 12. Resultados médios de emissões "baseline" em relação aos limites PL5 no ciclo NBR6601

Além das emissões, são apresentadas as variáveis monitoradas pelo sistema OBD. Estes dados foram tratados e analisados com o auxílio da ferramenta TOPexpert ${ }^{\circledR}$ desenvolvida pela FEV. No caso da diagnose do sensor de oxigênio, foi estudado o comportamento da frequência de comutação do sinal do sensor, referência para detectar o envelhecimento da sonda, o que leva a uma resposta mais lenta e consequente aumento nas emissões. A Figura 13 apresenta a distribução das frequências baseline em diferentes cargas do motor e para diferentes combustiveis ( $\mathrm{AF}=9$ corresponde a $\mathrm{E} 100$ e $\mathrm{AF}=13,2$ a $\mathrm{E} 22)$. 


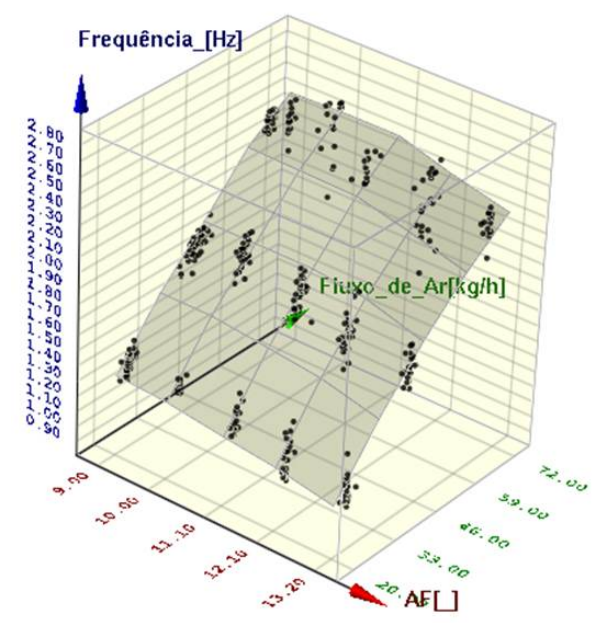

Figura 13. Distribução da frequência baseline do sensor de oxigênio para diferentes faixas de combustivel e fluxo de ar

No gráfico é observado um leve aumento na frequência quando utilizado etanol puro mantida constante a carga do motor. Também pode ser visualizado um aumento significativo na frequência quando o fluxo de ar aumenta. Os valores médios de frequência variam em torno de $1,40 \mathrm{~Hz}$ para cargas baixas e de $2,50 \mathrm{~Hz}$ para cargas altas.

No caso da diagnose do catalisador, utilizou-se o cálculo da OSC (Oxygen Storage Capacity) como medida do envelhecimento do componente. A OSC baseia-se na propriedade dos catalisadores de armazenar oxigênio durante fases pobres da mistura para depois liberá-lo nas fases ricas. Existe uma correlação entre a OSC e o nível de envelhecimento de um catalisador e, portanto, da eficiência de conversão dos poluentes.

A Figura 14 mostra a distribuição dos valores de OSC em função do fluxo de ar e do tipo de combustivel para um catalisador $80 \mathrm{~K}$. Estas medições foram realizadas em condições constantes de temperatura do catalisador. È perceptivel que a OSC é inversamente proporcional à quantidade de etanol no combustivel e à carga do motor.

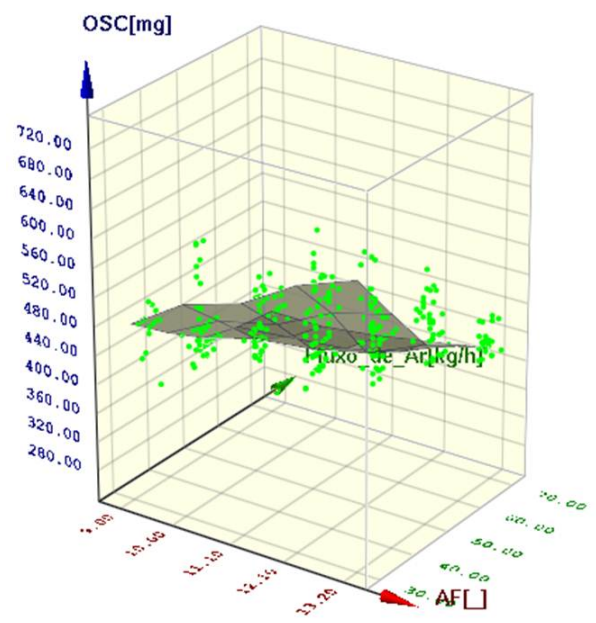

Figura 14. Distribução da OSC para um catalisador $80000 \mathrm{~km}$ em função da carga e combustivel 
Uma vez identificado o comportamento dos monitores de sonda e catalisador em qualquer faixa de combustivel em condições normais, há que se avaliar o impacto de falhas no sistema que possam levar ao acendimento da LIM. Os testes para simulação de erro de resposta lenta da sonda foram realizados com catalisador $80 \mathrm{~K}$, aplicando-se um retardo de $200 \mathrm{~ms}$ na resposta da sonda. A Figura 15 apresenta os resultados médios de emissões quando simulada a falha.

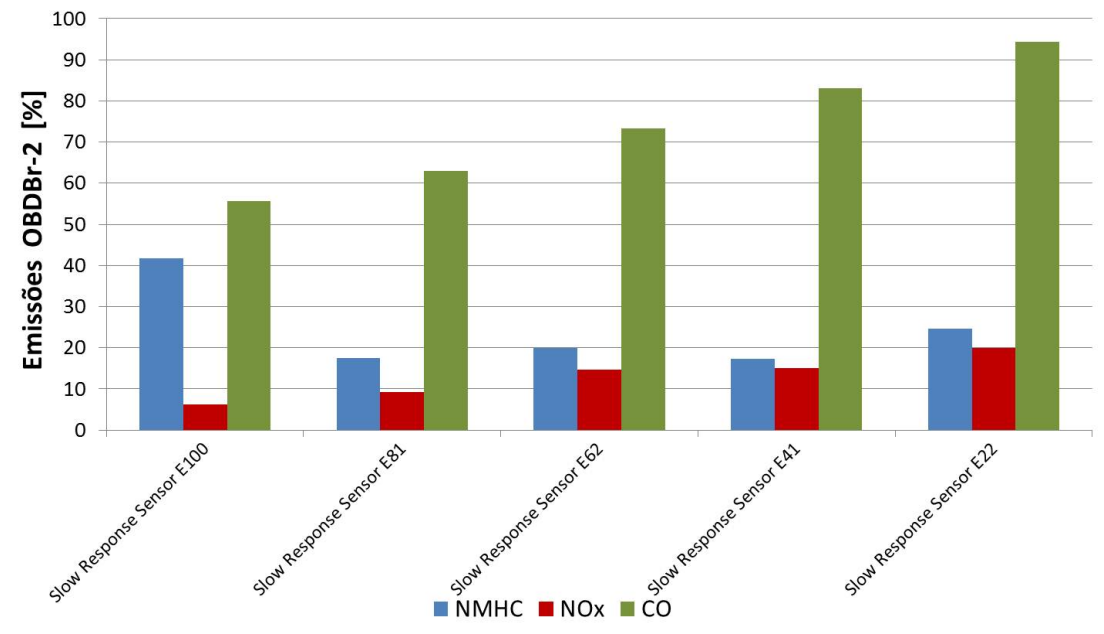

Figura 15. Resultados médios de emissões em relação aos limites OBDBr-2 no ciclo NBR6601, catalisador $80000 \mathrm{~km}$ e simulação de erro de resposta lenta da sonda

Fica clara uma relação entre o aumento dos niveis de $\mathrm{CO}$ quando o percentual de etanol no combustivel diminui. $\mathrm{O}$ valor máximo encontrado nos ensaios foi de aproximadamente $94 \%$ do limite $\mathrm{OBDBr}-2$, obtido com E22. Os outros gases poluentes não apresentaram valores significativos quando comparados com os limites OBD.

A frequência calculada pelo monitor de sonda mostra um comportamento similar aos resultados obtidos nos ensaios baseline, tendo valores máximos quando o combustivel é etanol puro e na região de carga alta do motor.

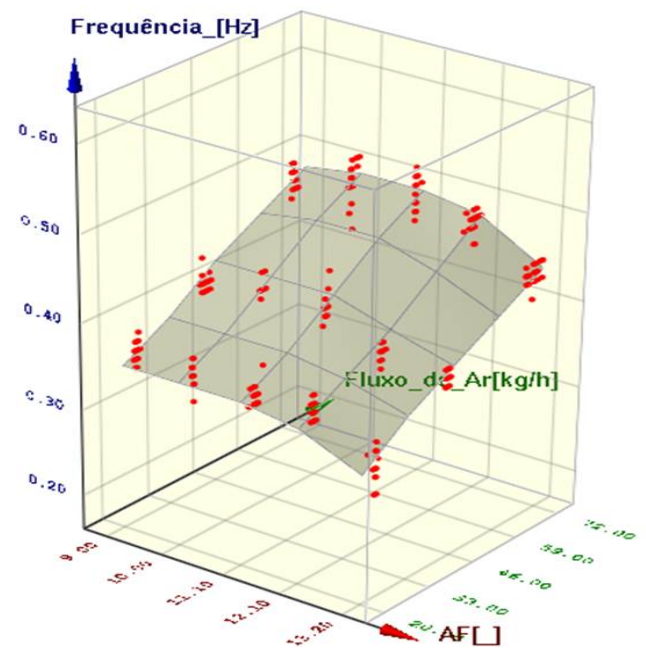

Figura 16. Distribução da frequência do sensor de oxigênio em diferentes faixas de combustivel e carga de motor, quando simulada a falha 
As Figuras 17 e 18 mostram a influência da carga e do combustivel no cálculo da frequência. Nota-se que a influência da carga é predominante, enquanto o combustivel tem menor importância, podendo ocasionar variações de até $7 \%$, que são facilmente absorvidas pela robustez da calibração.

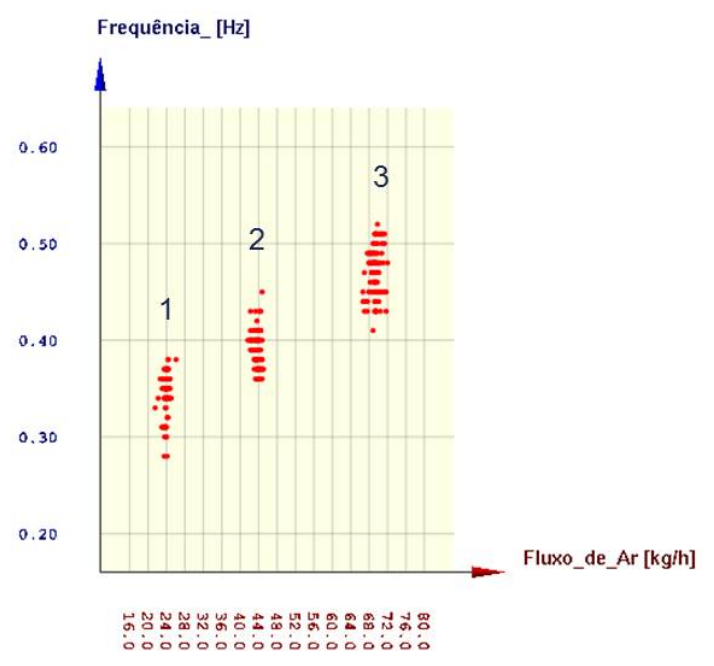

Figura 17. Variação da frequência do sensor de oxigênio em relação à carga do motor, quando simulada a falha

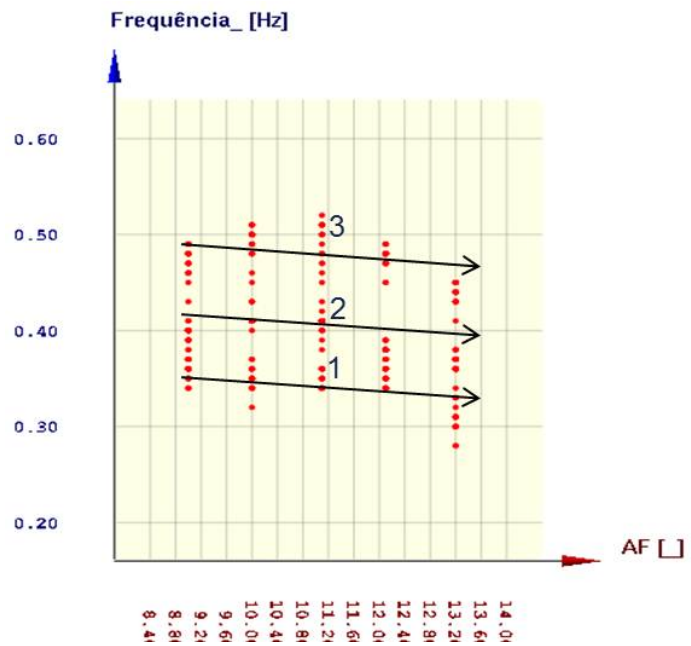

Figura 18. Variação da frequência do sensor de oxigênio em relação ao combustivel, quando simulada a falha

Avaliou-se a influência dos diferentes combustiveis na OSC em catalisadores envelhecidos que levam ao acendimento da LIM. Da Figura 19 é possivel extrair que o NMHC, mesmo sendo o único parâmetro da normativa exigido para a diagnose do catalisador, apresenta os menores resultados frente ao limite OBD. Por outro lado, os valores de NOx são os que mais se aproximam de tal limite. 


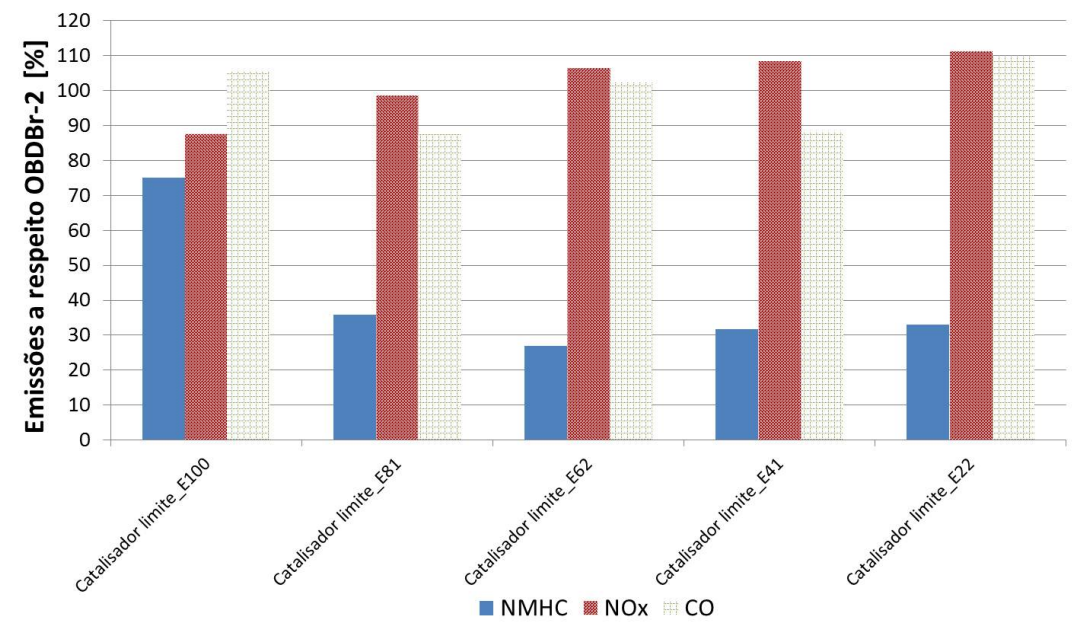

Figura 19. Resultados médios de emissões em relação aos limites OBDBr-2 no ciclo NBR6601, catalisador limite

As Figuras 20, 21 e 22 apresentam a OSC em função de carga e combustivel. Nota-se que a menor dispersão nos resultados encontra-se em cargas mais altas, como se vê na zona 4 nas figuras. Nesta zona, observa-se uma evidente proporcionalidade nos resultados de OSC entre E100 e E22, ou seja, os valores de OSC intermediários podem ser abrangidos por interpolação destes extremos, deixando perfeitamente clara a confiabilidade do sistema em todas as faixas de combustivel.

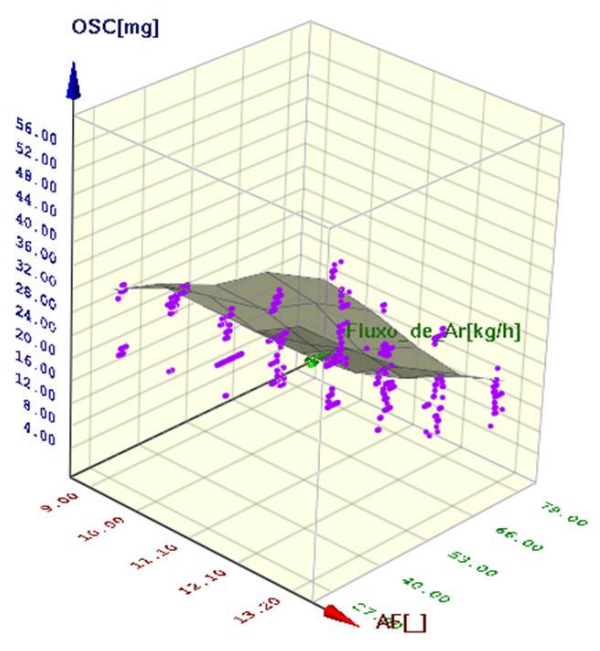

Figura 20. Distribuição da OSC para um catalisador limite em função da carga e combustivel 


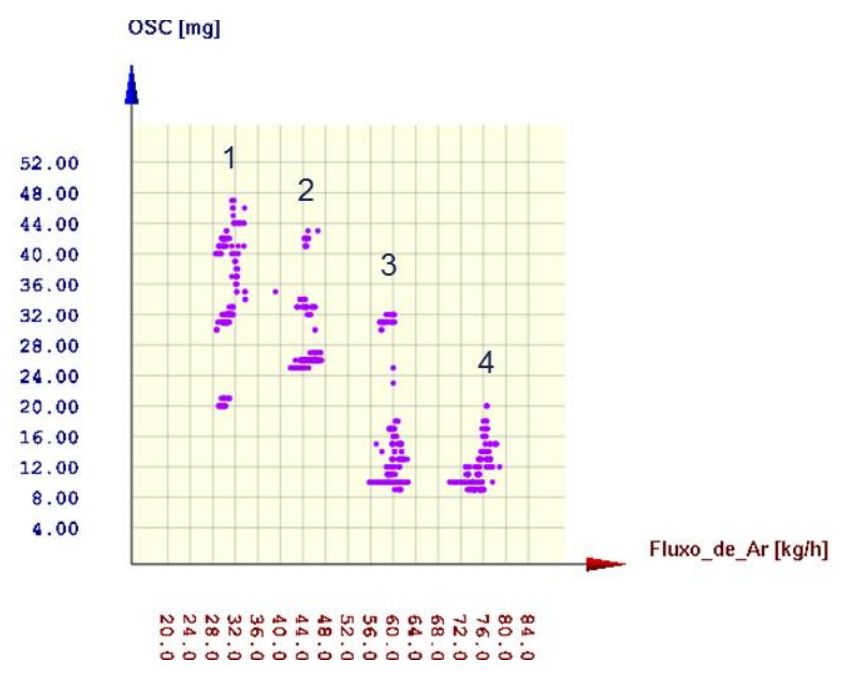

Figura 21. Variação da OSC em relação à carga do motor, catalisador limite

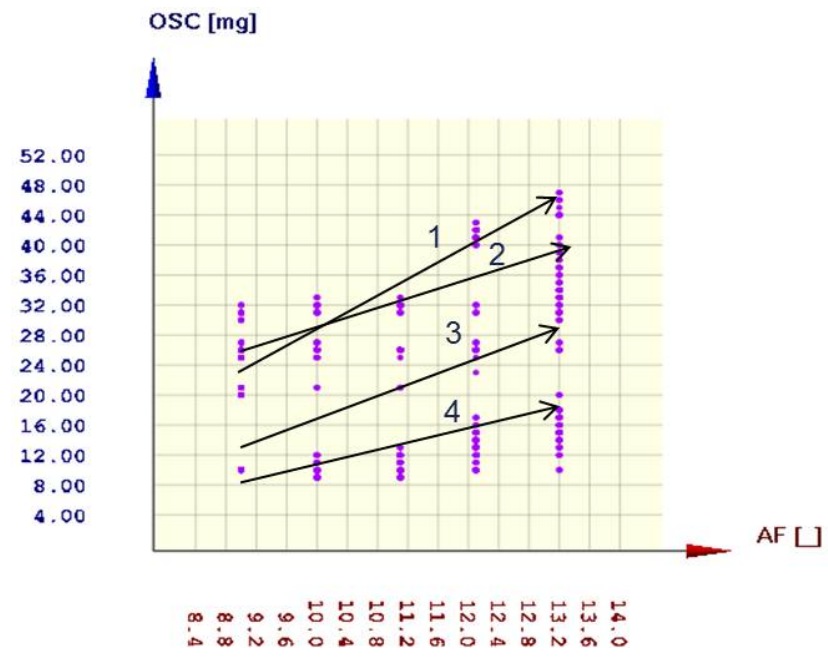

Figura 22. Variação da OSC em relação ao combustivel, catalisador limite

\section{INTRODUÇÃO DO LIMITE DE NOX PARA A DIAGNOSE DO CATALISADOR}

A diagnose do catalisador é uma das mais importantes dentre aquelas exigidas pelas normativas OBD pelo mundo, pois este componente é o principal responsável pelo abatimento das emissões de poluentes do veículo. Por se tratar de um componente de elevado custo, ele deve possuir uma grande durabilidade. Entretanto, o limite OBD no Brasil desta diagnose se baseia apenas na observação do nível de NMHC.

A partir de 2003, a CARB passou a realizar testes com veículos envelhecidos em campo e equipados com sistemas OBDII. Estas pesquisas mostraram que a eficiência na conversão de HC e NOx diminuia a taxas aproximadamente iguais [8]. Isto levou a CARB a concluir que a OSC, referência mais difundida nos sistemas de monitoramento da eficiência da conversão do HC, também estava relacionada à conversão de NOx [9]. A partir de 2006 tornou-se obrigatório nos Estados Unidos implantar um limite de NOx para a diagnose do catalisador, e na Europa com a EU5+ em 2010 introduziu-se também esta obrigatoriedade. 
Estudos mais recentes revelaram uma tendência de aumento mais intenso dos níveis de NOx do que de NMHC durante o envelhecimento do catalisador [10]. Ao se continuar com o envelhecimento do componente (Diminução dos valores de OSC) a tendência seria de estabilização das emissões de NMHC e, em alguns casos, em níveis inferiores ao limite OBD para este poluente, ao passo que, as emissões de NOx seguem em sensível aumento durante a utilização do veículo.

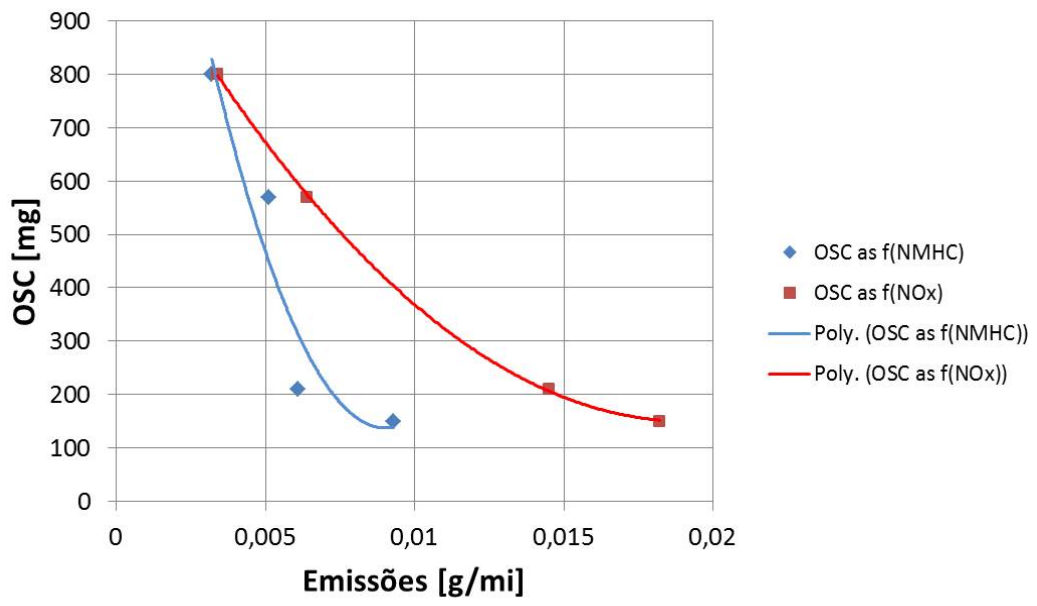

Figura 23. Correlação entre emissões de NMHC e NOx com a OSC [10]

Aprofundando-se neste tema, comparou-se os níveis de emissões obtidos em diferentes projetos utilizando-se os respectivos catalisadores limite. Neste cenário mostrado na Figura 24 , nota-se que os catalisadores dos projetos 1,2,4 e 5 apresentam um comportamento similar à tendência mostrada na Figura 23, tendo emissões de NMHC médias e de NOx altas. O catalisador 2 se apresenta como um caso extremo, com NMHC ainda dentro do limites OBD, porém com NOx quase duas vezes o limite. O catalisador do projeto 6 apresenta um comportamento quase linear entre dos dois poluentes. O catalisador 3 é um caso extremo no qual as emissões de NMHC são bastante baixas (próximas ao limite PL6) e emissões de NOx extremamente altas (13 vezes o limite legal). Cabe mencionar que este catalisador foi envelhecido em forno, um método pouco utilizado atualmente, por não ser representativo do envelhecimento real.

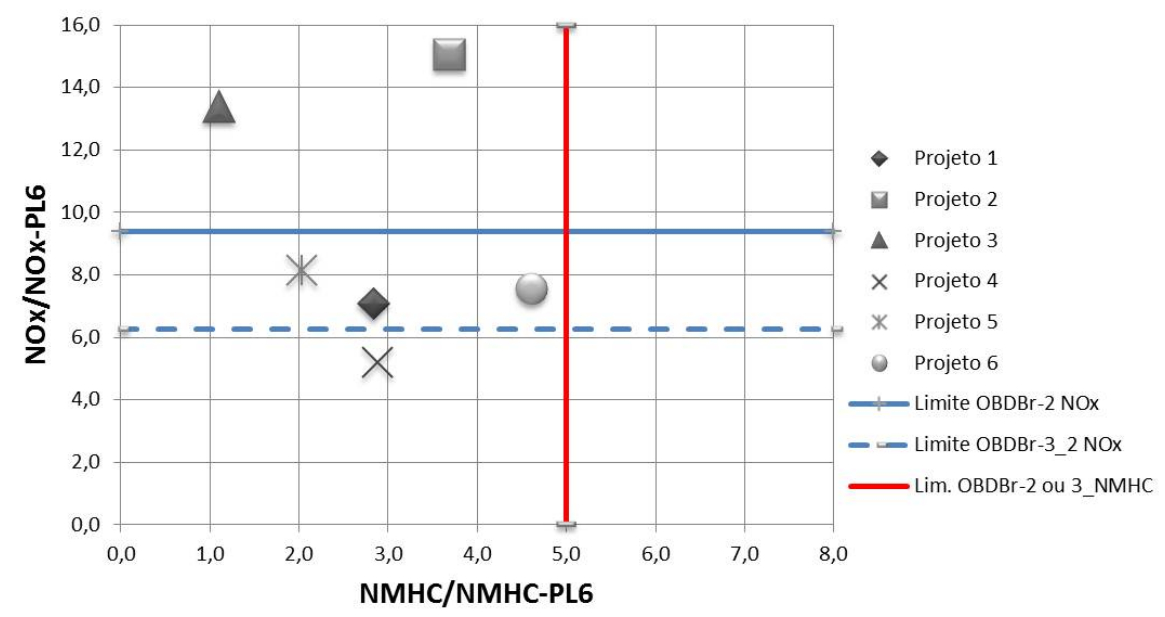

Figura 24. Emissões dos catalisadores envelhecidos em relação aos limites OBD 
A linha tracejada na Figura 24, mostra o limite de NOx do cenário OBDBr3_"2" apresentado neste trabalho. Apenas o catalisador do projeto 4 atenderia a este cenário.

Estes resultados permitem compreender que a implantação de um limite de NOx para o diagnose de catalisador, não só aproximaria a normativa OBD do Brasil aos mais altos padrões internacionais, como também reduziria significativamente o impacto ambiental do NOx, ao conseguir identificar catalisadores degradados além dos limites OBD.

\section{CONCLUSÕES}

O objetivo deste trabalho foi demonstrar que, seguindo a linha na redução dos limites de escapamento introduzidos a partir de 2014 com a legislação Proconve L6, é preciso reavaliar a normativa OBD no Brasil, acompanhando a evolução destes sistemas nos mercados mais exigentes do mundo. Foram apresentados três diferentes cenários para a evolução da normativa OBDBr-2:

- Redução dos limites OBD a valores mais representativos com a tendência mundial, e introdução do limite NOx para a diagnose do catalisador;

- Aumento da durabilidade exigida para a frota de automotores leves, levando em consideração o ciclo real de vida dos veículos no Brasil (Aumento dos fatores de deterioração);

- Obrigatoriedade do monitoramento em qualquer faixa de combustível para o sensor de oxigênio e o catalisador.

Os resultados desta pesquisa permitem concluir que é perfeitamente viável implementar estas propostas, promovendo assim a evolução dos sistemas de monitoramento no país, o que traria reflexo positivo do ponto de vista ambiental. 


\section{REFERÊNCIAS}

[1] MINC, Carlos. I Inventário Nacional de Emissões Atmosféricas por Veículos Automotores Rodoviários. Disponível em

http://www.mma.gov.br/estruturas/182/_arquivos/inventrio_de_emisses_veiculares_182.pdf,

Data de acesso: 11.04.2013

[2] DUQUE, Oscar; ROEWER, Guido; FURLAN, Paolo; BUCCI, Alberto. “OBD no Brasil, suas particularidades e desafios futuros" XIX Simpósio Internacional de Engenharia Automotiva SIMEA 2011

[3] KORTENOEVEN, Dennis. "Influence EOBD V/VI on OBD Gasoline Engine

Calibration". CTI Konferenz "On-Board Diagnose auf dem europäischen Markt", FEV Motorentechnik, 2008

[4] SINDIPEÇAS, "Levantamento da frota circulante brasileira em 2011". Disponível em http://www.sindipecas.org.br; Data de acesso: 02.03.2013

[5] MURGEL, Gabriel; CARDINALE, Fábio; SZWARC, Alfred. "Relatório de avaliação do programa IM-SP: Descritivas e resultados de veículos com motor do ciclo Otto em 2011". São Paulo, junho de 2012

[6] Ministério do Meio Ambiente, Instituto Brasileiro do Meio Ambiente e dos Recursos Naturais Renováveis. Instrução Normativa N. ${ }^{\circ}$ 24, de 28 de agosto de 2009

[7] EPE, Empresa de Pesquisa Energética e Ministério de Minas e Energia. "Avaliação do comportamento dos usuários de veículos flex fuel no consumo de combustíveis no Brasil". EPE-DPG-SDB-Bios-NT-01-2013

[8] TSINOGLOU, Dimitrios, MELLIOS, Georgios, XANTHOPOULOS, Anastassios. "Impact assessment/On Board Diagnostic (OBD) Systems for passenger cars, final report". Aristotle University Thessaloniki, Greece, 2005

[9] BALTUSIS, Paul, VANGILDER, John, Zatorski, Hal. "New OBDII Monitor

Requirements". OBDII TOPTEC, Pasadena, California, 2005. Disponível em http://www.sae.org/events/training/symposia/obd/presentations/2005baltusis3.pdf; Data de acesso: 13.04.2013

[10] DUQUE, Oscar, "Method for the Diagnosis of a Catalytic Converter at Idle for a SULEV System with a new Catalytic System”. Master Thesis, RWTH Aachen University, Germany, 2008 